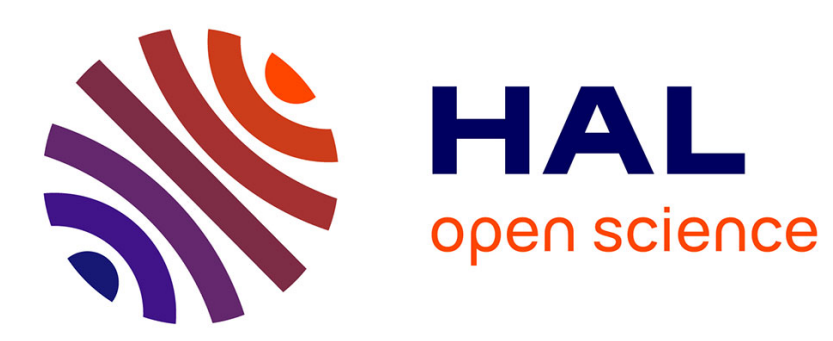

\title{
Raman and IR micro-analysis of high performance polymer fibres tested in traction and compression
}

Ph. Colomban, Gwenaël Gouadec

\section{To cite this version:}

Ph. Colomban, Gwenaël Gouadec. Raman and IR micro-analysis of high performance polymer fibres tested in traction and compression. Composites Science and Technology, 2009, 69 (1), pp.10. 10.1016/j.compscitech.2007.10.034 . hal-00563491

\section{HAL Id: hal-00563491 https://hal.science/hal-00563491}

Submitted on 6 Feb 2011

HAL is a multi-disciplinary open access archive for the deposit and dissemination of scientific research documents, whether they are published or not. The documents may come from teaching and research institutions in France or abroad, or from public or private research centers.
L'archive ouverte pluridisciplinaire HAL, est destinée au dépôt et à la diffusion de documents scientifiques de niveau recherche, publiés ou non, émanant des établissements d'enseignement et de recherche français ou étrangers, des laboratoires publics ou privés. 


\section{Accepted Manuscript}

Raman and ir micro-analysis of high performance polymer fibres tested in traction and compression

Ph. Colomban, G. Gouadec

PII: S0266-3538(07)00430-7

DOI: 10.1016/j.compscitech.2007.10.034

Reference: CSTE 3879

To appear in: Composites Science and Technology

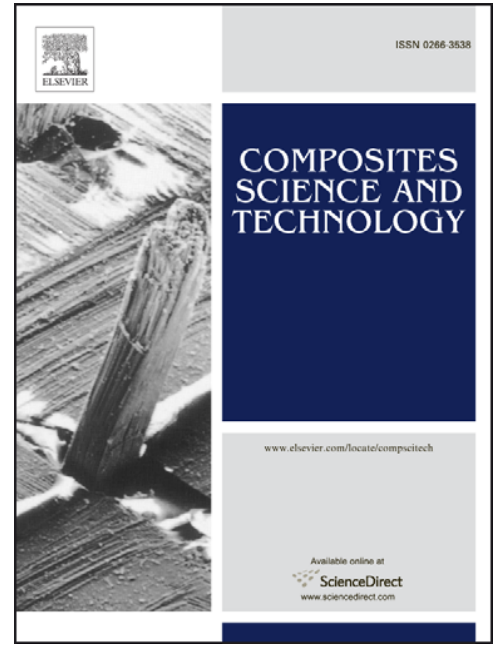

Received Date: $\quad 14$ May 2007

Accepted Date: $\quad 11$ October 2007

Please cite this article as: Colomban, Ph., Gouadec, G., Raman and ir micro-analysis of high performance polymer fibres tested in traction and compression, Composites Science and Technology (2007), doi: 10.1016/j.compscitech. 2007.10.034

This is a PDF file of an unedited manuscript that has been accepted for publication. As a service to our customers we are providing this early version of the manuscript. The manuscript will undergo copyediting, typesetting, and review of the resulting proof before it is published in its final form. Please note that during the production process errors may be discovered which could affect the content, and all legal disclaimers that apply to the journal pertain. 


\title{
RAMAN AND IR MICRO-ANALYSIS OF HIGH PERFORMANCE \\ POLYMER FIBRES TESTED IN TRACTION AND COMPRESSION
}

\author{
Ph. Colomban*, G. Gouadec \\ Groupe des Nanophases et Solides Hétérogènes \\ Laboratoire de Dynamique, Interaction et Réactivité (Ladir) \\ UMR 7075 CNRS \& Université Pierre et Marie Curie \\ 2 rue Henri Dunant 94320 Thiais, France \\ * corresponding author, e-mail : philippe.colomban@glvt-cnrs.fr
}

\begin{abstract}
The analysis of the (nano)structure and texture of polymer fibres (polyamides 66, Bombyx mori and spider silks) by Raman (IR) microscopy/metry, in particular after deuteration and isotopic H/D dilution, is applied so as to differentiate between crystalline and amorphous macromolecules. Bonding is very similar in the two cases but a broader distribution of conformations is observed for the amorphous macromolecules, in agreement with the para-crystal model. These conclusions are then used to discuss the modifications induced by the application of a tensile or compressive stress, including the effects of fatigue. Detailed attention is paid to water and the inter-chain coupling for which the importance of hydrogen bonding is reconsidered. The significant role of the "amorphous" bonds in the process of fracture/fatigue is shown. The approach is extended to the analysis of silks.
\end{abstract}

KEYWORDS : Fibres, Polymers, Raman spectroscopy, Infrared (IR) spectroscopy, Deformation 


\section{INTRODUCTION}

The behaviour of fibres in compression and tension is not well known. It is not only the case for new systems like, for example, the PBO Zylon ${ }^{\mathrm{TM}}$ (paraphenylenebenzonitrozyl) but also for "older materials" like polyamide fibres (Nylon $^{\mathrm{TM}}$ and counterparts) or high performance natural fibres (Bombyx mori or spider silks). On the basis of X-Ray diffraction, the fibres are described as composed of areas with variable crystallinity (crystallized, "oriented amorphous" and "amorphous" matter [1]). The distribution of these zones along the fibres and across their section (skin/core gradient) is unknown in the vast majority of the cases.

Usual crystallographic descriptions assume zones of different crystallinity can be identified but it is difficult to differentiate a progressive orientational disorder (paracrystal model from Von Hoseman) and a juxtaposition of more or less ordered domains [2] in the reciprocal space (where X-ray diffraction is performed). The identification between the domains -or crystallite size (Scherrer formula) - and the coherence length is reasonable in metals, or in ionic compounds, but not necessarily in molecular compounds. It is indeed much easier, from an energetic point of view, to deform covalent bond angles than to stretch the inter atomic distances. The continuous deformation para-crystal model (i.e. without origin nor borders) therefore seems more reasonable, although little considered in the literature.

In many fibres, inter-chain hydrogen bonds are assumed to form around overlaps, crossings, loops.... It is supposed that these conditions, at the same time, control the performance of the fibre, in rigidity (tension of the molecular chains) and elasticity (disentanglement and tension of the chains of the amorphous zones) and in additon, the modes of fatigue and failure (initiation, propagation). Let us note that bridging is 
more complex in silks (molecular bridges) and that, contrary to the hydrogen bond which weakens when it is stretched, it is likely to become more rigid. Complex processes of extrusion-extension or spinning from a liquid state crystal regulate the texture of high performance synthetic fibres. The mechanisms correlating texture and nano-/micro-properties remain to be clarified. We will try here to present the broad possibilities that IR and Raman microscopes offer in the study of the texture and the (nano)mechanical behaviour of fibres $[3,4]$ by closely analysing the spectra with the techniques of deuteration developed for the study of compounds with hydrogen bonding (protonic conductors in particular [5]). We will take PA66 polyamide fibres (used in tyres and cables) as an example and we will make a comparison with natural fibre precursors (silks) on the basis of a work carried out in collaboration with Drs Anthony Bunsell and Roland Picques from the Ecole des Mines de Paris [1,3,4,6]. An analysis of the whole of the spectrum allowed the selection of the most relevant probes:

i) low-frequency modes around $50-100 \mathrm{~cm}^{-1}$, corresponding to collective movements ( $\mathrm{T}_{\text {chains}}$ ) and representing the shearing-friction of the macromolecule chains,

ii) modes of hydrogen bonded $\mathrm{N}-\mathrm{H}$ vibrators probing the inter-chain distances,

iii) amid I modes characterizing the chain modification $\left(\sim_{\mathrm{C}=\mathrm{O}} ; \mathrm{C}-\mathrm{C}\right)$.

The analysis in (load or strain-) controlled traction and hydrostatic compression (in a diamond anvil cell [6]) clearly highlights different thresholds of tension/compression for "crystalline" and "amorphous" bonds, in agreement with the macroscopic mechanical analyses. We will focus our discussion on the differentiation of bonds belonging to a crystalline "area" from those pertaining to "amorphous areas" by using the technique of isotopic dilution H/D [5]. The conclusions will be applied to the 
discussion of recently published results on measurements under controlled stress $[3,4,6]$.

\section{EXPERIMENTAL}

Samples: The fibres (diameter between $\sim 15$ (silk) and $\sim 30($ PA66) $\mu \mathrm{m}$ ) are either cut in pieces a few $\mathrm{cm}$ long. Fibre tips are taped onto glass (or metal) plates, or assembled in a universal tester [1]. Some fibres are dried at various temperatures or encapsulated with water $\left(\mathrm{H}_{2} \mathrm{O}\right)$ or heavy water $\left(\mathrm{D}_{2} \mathrm{O}\right)$ in long Pyrex tubes of about fifteen $\mathrm{cm}$ in length, sealed under primary vacuum, of which the lower part is heated up to various temperatures $\left(>100{ }^{\circ} \mathrm{C}\right)$ for variable times. PA66 fibres of various producers were tested, certain being hydrolyzed too quickly to carry out the H/D exchange. The tube is eventually broken and the fibres examined immediately and over the following days, in order to apprehend the changes due to the exchanges with ambient moisture. Silk was studied either in the gel state, directly in the Bombyx mori glands, or in the threaded state.

Microspectrometries:

- The Raman spectra were recorded at room temperature with two spectrometers equipped with lasers delivering various lines; the illumination and the collection of the diffused signal is achieved through microscope objectives, with magnifications of x100 / x1000. In confocal configuration, the maximum lateral space resolution (x1000) of the Raman imagery is $\sim 0.5 \mu \mathrm{m}$ ( 3-5 times larger along $\mathrm{z}$ direction). A motorized XY table makes it possible to carry out cartographies with a step $0.1 \mu \mathrm{m}$ on the two apparatuses. The power on the sample is measured using a a PD200 photodiode detector. The following instruments were used: 
i) a XY spectrometer (Dilor, Lille, France) with high resolution and medium sensitivity using the lines of a $\mathrm{Ar}^{+}-\mathrm{Kr}^{+}$laser $(647.1 \mathrm{~nm}, 514.5 \mathrm{~nm}, 457.9$ $\mathrm{nm})$, a double monochromator and a CCD detector cooled to $140 \mathrm{~K}$ by liquid nitrogen (resolution of $\sim 0.5 \mathrm{~cm}^{-1}$ ). The low intensity of the Raman signal requires long times of recording.

ii) a Infinity spectrometer (Horiba Jobin-Yvon SAS, Longjumeau, France) with medium resolution and high sensitivity (Notch filter) equipped with a He-Ne $(632.8 \mathrm{~nm})$ and a doubled Nd:YAG $(532 \mathrm{~nm})$ lasers. The CCD detector is cooled by air and Peltier effect (resolution $\sim 2 \mathrm{~cm}^{-1}$ ).

Labspec software (Dilor) was used for the subtraction of a linear base line and the elimination of the electronic and cosmic peaks from the spectra. Origin software (Microcal Inc, USA) was then used to fit the various components with a Lorentzian (L) shape for the "crystalline/molecular" modes and a Gaussian (G) shape whenever a distribution of configurations was expected ("amorphous" signal). A lab-developed software called "PARADIS" was used for the linescans/mappings [7].

- The straining of the fibres was obtained with a device that compensates for the inelastic lengthening and, thereby, maintains a constant stress, as described in [1]. Measurements under hydrostatic pressure are taken through a diamond anvil cell, the pressure being calibrated with the fluorescence lines of chromium ions in ruby crystals [6].

- the infra-red microscope/ATR is an Equinox 55 Fourier Transform Michelson interferometer (Bruker, France) with a ATR "golden gate" input. It is designed to examine the surface (a few microns) of a material brought into "perfect" contact with the ATR crystal. A "Irscope II" microscope with Cassegrain objectives makes it also 
possible to work in transmission. The spot diameter $\sim 200 \mu \mathrm{m}$ is reduced to $\sim 20 \mu \mathrm{m}$ with a diaphragm, to separately analyse the core and skin of a fibre.

\section{RESULTS}

\section{"CRYSTALLINE"/"AMORPHOUS" CONFORMATIONS}

IR and Raman spectroscopes probe the matter through mechanics (wavenumbers = vibrational eigenfrequencies) and the inter-atomic/molecular charge transfers (the peak intensity is either a direct (IR) or an indirect (Raman - requires multiplication by the frequency) measurement of conductivity [5]). Not only the position (wavenumber) but also the form (Lorentzian or Gaussian), the width, and the polarized modes of the Raman and IR components give valuable information on the composition (elongation modes are characteristic of the chemical bonds or molecular functions), the structure (polarizations and collective low energy modes) and the texture (polarization mappings) of the fibres. The comparisons of polarized signatures for $/ /(\mathrm{H})$ and $\perp(\mathrm{V})$ configurations obtained by changing the orientation of the fibre with respect to the spectrometer slit entrance, is a good mean of measuring the axial character of the fibre. In the case of the $\mathrm{X}-\mathrm{H}$ vibrators, the intrinsic mode width (resulting from the structural disorder alone) is obtained only in the case of an isotopic dilution $[\mathrm{H}] /[\mathrm{D}]<10 \%$ : very light vibrators normally couple in a complex way (mechanical, electric, quantum) with the other phonons and only isotopic dilution, by removing the essence of these couplings, it becomes possible to obtain a spectrum giving details on the vibrators environment [5]. Figure 1 compares the Raman signature of the PA66 fibre in its hydrogenated and deuterated forms : only some modes shift and the absence of hydrolysis is therefore shown. Figure 2 
compares the signature of silk raw material (spectra directly recorded on the Bombyx mori silkworm dry glands) with that of a spider thread. The spectral signature of the amide group is systematically present, as observed for the PA66 fibre (Fig.1). Assignments can be found in refs. [3,8-10]. Figures 3, 4 and 5 compare the detail of the signatures of the low frequency collective modes and the N-H groups, respectively. The comparison of the polarized Raman signatures and IR spectra in the $3200-3600 \mathrm{~cm}^{-1}$ spectral window, where elongation modes $\mathrm{N}-\mathrm{H}$ and $\mathrm{O}-\mathrm{H}\left(\mathrm{H}_{2} \mathrm{O}\right)$ are expected (with some combinations), shows several quite polarized components (Table 1) : the main component is the narrowest Raman peak at $\sim 3303 \mathrm{~cm}^{-1}$ (band width at half height $\sim 30 \mathrm{~cm}^{-1}$, reduced to $\mathrm{L}=20 \mathrm{~cm}^{-1}$ in diluted $\mathrm{H} / \mathrm{D}$ isotopic polyamide fibre). The IR counterpart peaks at $3304 \mathrm{~cm}^{-1}$ (band width $\sim 100 \mathrm{~cm}^{-1}$, reduced to $\mathrm{L} \sim 40 \mathrm{~cm}^{-1}$ in diluted H/D isotopic polyamide fibre). These narrow peaks are well described with a Lorentzian function and can be assigned to crystalline macromolecular chains. Similarly to the translational $\mathrm{T}^{\prime}$ ch collective modes (around $100 \mathrm{~cm}^{-1}$ ), it shows a strong $\mathrm{V}(/ /)$ polarized character. The wavenumber is insensitive to isotopic dilution (Table 1) and the peak corresponds well to a N-H vibrator almost free from any hydrogen bonds $\left(\mathrm{d}_{\mathrm{N}-\mathrm{H} . . \mathrm{O}}>0.293 \mathrm{~nm}\right.$, see $\left.[5,6]\right)$. In orthogonal polarization the intensity of this Lorentzian Raman component strongly decreases to the benefit of a broader Gaussian component ( $L, \sim 80 \mathrm{~cm}^{-1}$, Fig.5), ascribable to the "amorphous" macromolecules. The higher wavenumber $\left(G, \sim 3310 \mathrm{~cm}^{-1}\right)$ indicates an absence of hydrogen bond, in agreement with a less compact structure. Two other weak bands are observed but it is difficult to know whether they both correspond to other types of $\mathrm{N}-\mathrm{H}$ vibrators, or more probably to combinations, or result from a bad description of the line-shapes. The conservation of an amorphous component in polarization $\perp(\mathrm{V})$ confirms the isotropic character of the amorphous connections. Water saturation 
involves an increase in intensity of certain modes (Table 1). The Raman cross section of the $\mathrm{O}-\mathrm{H}$ vibrators being very weak, a discussion on the water content has to rely on the IR spectra obtained with the Irscope (Fig. 4), in particular using the band at 3450 $\mathrm{cm}^{-1}$ that strongly weakens after drying. Two other well-known characteristics in the case of compounds containing amide groups are also visible, the splitting of the N-D mode (which does not relate to the existence of two N-D bonds) and a strong N-H combination towards $3075 \mathrm{~cm}^{-1}$ [8]. The shape of the IR bands being less well defined than in Raman diffusion, the measurement of the [crystalline/amorphous] proportion is coarser. Let us note that the re-hydrogenation of the deuterated fibres is slow and no notable difference between a spectrum carried out a few minutes after exiting the bulb or 1 hour afterwards is observed.

The whole of these results confirms the existence of "crystalline" and "amorphous" or, rather, ordered and disordered conformation/structures of the macromolecular chains. The R/IR splitting being almost inexistent in the isotopically diluted state, so it may be concluded that the local "crystalline" and "amorphous" structures in PA 66 fibre are very similar and thus in agreement with a model of continuous angular disorder (para-crystal). The presence of two components at $\sim 3280$ and $3220 \mathrm{~cm}^{-1}$, indicate that 5 to $10 \%$ of $\mathrm{N}-\mathrm{H}$ vibrators are engaged in stronger, 0.286 to $0.289 \mathrm{~nm}$ long hydrogen bonds, according to a ${ }_{\mathrm{N}-\mathrm{H}}=\mathrm{f}\left(\mathrm{d}_{\mathrm{N} \ldots \mathrm{O}}\right)$ correlation [6]. The latter could correspond to inter-chain anchoring points (twists, helices ?). A disturbance by the presence of water molecules, also engaged with hydrogen bond is not excluded.

This analysis agrees with the results of X-ray diffraction highlighting crystalline and amorphous "phases" and validates the choice to apply this description to the collective mode around $100 \mathrm{~cm}^{-1}$. The fact that the $\mathrm{N}-\mathrm{H}$ wavenumber of the 
amorphous "phase" is a little higher is in agreement with the lower energy of the corresponding $\mathrm{T}_{\text {ch }}$ collective mode, as observed in Fig.3. Let us note the nearly complete disappearance of the "crystalline" component signature in $\perp$ polarization. Therefore, the analysis of the $\mathrm{T}_{\text {chains }}^{\prime}$ modes at 100 (crystalline) $/ 70$ (amorphous) $\mathrm{cm}^{-}$ ${ }^{1}$ confirms the alignment of the crystalline macromolecular chains and the isotropic character of the amorphous ones. For silks, this character is less marked and variable, according to the type of silk considered.

\section{CORE/SKIN TEXTURES}

The recording of series of spectra across the fibre diameter (fig. 2) makes it possible to analyse the texture anisotropy of the various fibres (fig. 6). A core-skin effect is obvious $[1,3,4]$ from the wavenumber shift across the fibre diameter. These variations indicate a weak tension of the crystalline chains and a strong compression of the amorphous bonds in the fibre core. The strong width reduction of the "amorphous" macromolecular chain component in the fibre core undoubtedly indicates a much better organization, at the local scale, of the amorphous "phase". This characteristic can be related to the slower cooling of the fibre core. Comparison of the data recorded for fibres thermally treated at various temperatures below and above the $\mathrm{Tg}$ temperature shows that the core/skin anisotropy disappears by annealing above $T_{g}$ (Fig.6).

\section{STRESS AND FATIGUE}

The tensile behaviour of the crystalline and amorphous macromolecular chains can be investigated by follow-up of the collective mode $T_{\text {chains }}[3,4]$. This shows an initially viscoplastic behaviour until $450-500 \mathrm{MPa}(\sim 10-12 \%$ of lengthening), slightly varying according to the fibre producer. The amorphous bonds, firstand later the 
crystalline ones, are put into increasingly rigid elastic tension (Fig. 7, [4]). The thresholds measured on the scale of the molecular bonds correspond to the transitions on the stress-strain curve between an initial softening, a pseudoelastic regime and a non-linear pre-rupture. This behaviour is very similar to that of a composite material with initial loading of the matrix alone (the amorphous matter), then that of the reinforcement (continuous ordered macromolecular chains) and the matrix simultaneously and, eventually, the degradation of the matrix followed by that of the reinforcement. The analysis of fibres broken in fatigue highlighted a state of compressive stress of the amorphous phase close to the point of initiation of the rupture and its progressive decrease over 200 to $300 \mu \mathrm{m}$ beyond this point, all occurring as if the rupture in fatigue resulted from the loss of viscoelasticity, at certain points, of the amorphous phase. Under hydrostatic pressure the coming together of the chains (reduction in $\mathrm{N}-\mathrm{H}$ ) can be clearly seen and the existence of a threshold from which the geometry of the fibres is modified.

\section{CONCLUSION}

The possibility of separately analysing "crystalline" and "amorphous" macromolecule conformation/structure allows a better comprehension of the processes of (nano)rupture and fatigue. The key role of the bonds of amorphous macromolecular chains is confirmed whereas hydrogen bonds seem too weak to influence the mechanics of the system. The comparison with natural silks shows that this study could be generalized.

The authors warmly thank Drs A. Bunsell, G Chavancy, A. Marcellan and J.M. Herrera Ramirez and Mrs. G. Sagon and F Fayollet for their contribution to this work. 


\section{REFERENCES}

1. Marcellan A, Bunsell AR, Piques R et Colomban Ph, 2003. «Micro-Mechanisms, Mechanical Behaviour and Probabilistic fracture analysis of PA 66 fibres", J. Mater. Sci., v. 38, pp 2117-23.

2. Guinier A, 1956. Théorie et technique de la radiocristallographie, Dunod, Paris.

3. Marcellan A, Colomban Ph, Bunsell A. (Nano)structure, Internal Stress and in situ Fracture Behaviour of Polyamide Fibres. J. Raman Spectr 2004; 35(4): 308-315.

4. Hererra-Ramirez J.M, Colomban Ph, Bunsell A. MicroRaman Study of the Fatigue Fracture/Tensile Behaviour of Polyamide (PA66) Fibres. J. Raman Spectr 2005; 35(12): 1063-1072.

5. Colomban Ph, Ed. "Proton Conductors", Cambridge: Cambridge University Press, 1992.

6. Colomban Ph, Sagon G, Lesage M, Herrera Ramirez JM. MicroRaman Study of the Compressive Behaviour of Polyamide (PA66) Fibres in a Diamond -Anvil Cel. Vibrational Spectrosc 2005; 37(1): 83-90.

7. Havel M, Baron D, Colomban Ph. Smart Raman/Rayleigh Imaging of Nanosized SiC Materials Using the Spatial Correlation Model. J. Material Sci 2004; 39 (20): 6183-6190.

8. Cooper SJ, Coogan M, Everall N, Priesnall I. A polarised m-FTIR study on a model system for nylon 66: implication for the nylon Brill structure. Polymer 2001; 42: 10119-10120.

9. Maddams WF, Royaud IAM. The application of Fourier transform Raman spectroscopy to the identification and characterisation of polyamides -II. Doublenumber nylons. Spectrochimica Acta Part A: Mol. Spectrosc 1991; 47: 1327- 


\section{ACCEPTED MANUSCRIPT}

1333.

10. Monti P, Taddei P, Freddi G, Asakura T, Tsukuda M. Raman spectrocopic characterization of Bombyx mori silk fibroin : Raman spectrum of Silk I. J. Raman Spectrosc 2001; 32: 103-107. 


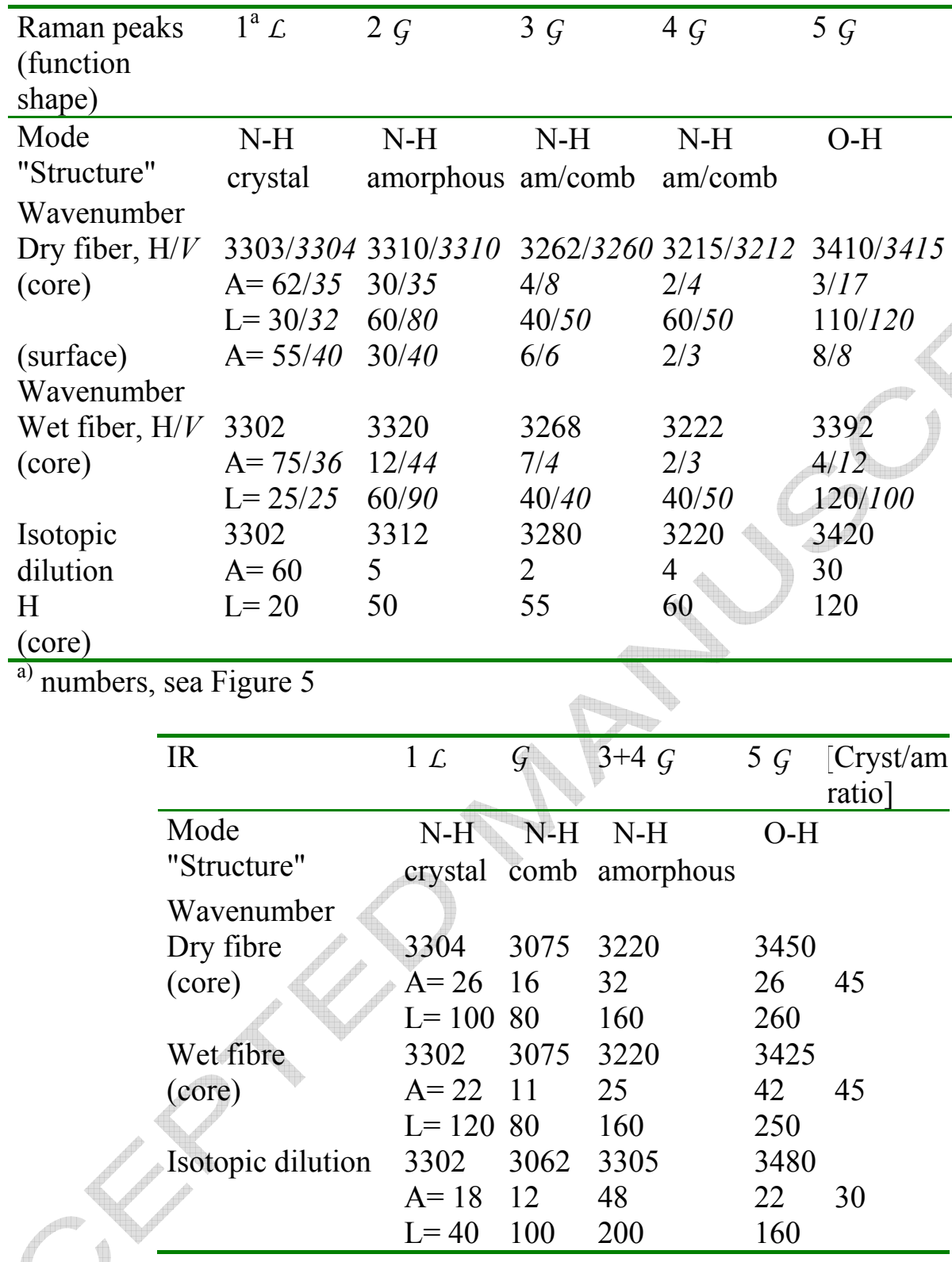

Table 1 : Wavenumber, area (A) and bandwidth at half height (L) of X-H modes in Raman and IR spectra of PA66 dry and wet fibres. Spectra recorded on dry Hisotopic diluted fibre are also given. Comparison is made between surface and core measurements. The peak area ratio (\%) is used to measure the proportion of "crystalline" to "amorphous" bonds in parallel $(\mathrm{H})$ and perpendicular (V) polarizations. ( $\mathcal{L}$ : Lorentzian; $G$ : Gaussian). Areas labeled "5" are an indirect measurement of the water content ; comb : combination mode. 


\section{FIGURE CAPTIONS}

Figure 1 : Polarized Raman spectra of PA66 fibres (top, hydrogenated; bottom, after nearly complete deuteration; // (H) and $\perp(\mathrm{V})$ polarization).

Figure 2 : Polarized Raman spectra of Bombyx mori wormsilk gland (colourless sericine-poor $(\mathrm{Bx})$ and yellow sericine-rich (By) gels) and spider silks; note the complex twisted dragline of spider silk and the perfectly cylindrical PA 66 fibre.

Figure 3 : Collective $\mathrm{T}^{\prime}$ chain Raman modes in $/ /$ and $\perp$ polarization for PA66 fibres and for dry Bombyx worm silk gel. Broad and narrow components respectively show amorphous and crystalline conformations.

Figure 4 : X-H(X-D) IR signatures of water saturated (" $\mathrm{H}_{2} \mathrm{O}$ "), standard (PA66) and isotope diluted PA66 single fibre.

Figure 5 : X-H(X-D) Raman signature of single PA66 fibres (top : // (H) and $\perp(V)$ polarization for a dry hydrogenated fibre; bottom, //polarization of a H/D diluted PA66 fibres (H/D 0.1), 3 minute (top) and 1 hour (bottom) after removing from controlled $\mathrm{D}_{2} \mathrm{O}$ atmosphere.

Figure 6 : wavenumber (top) and bandwidth at half height (bottom) for $\mathrm{T}^{\prime}$ 'hains modes (amorphous and crystalline components) across a PA66 fibre diameter ; centre : evolution as a function of the thermal annealing around $\mathrm{T}_{\mathrm{g}}\left(\sim 45^{\circ} \mathrm{C}\right)$ according to $[4$. 
Figure 7 : top, absolute wavenumber shift of the amorphous $\mathrm{T}_{\text {ch }}$ peak as a function of applied stress for a single PA66 fibre. Comparison is made with the wavenumber shift measured for fibres broken in tensile fatigue (after [4]). Centre and bottom, wavenumber shift measured for the amide $\quad \mathrm{CO}$ ) signature and $\mathrm{NH}$ stretching wavenumber as a function of the hydrostatic pressure applied on a PA66 fibre fragment in a Diamond anvil cell (after [6]). 

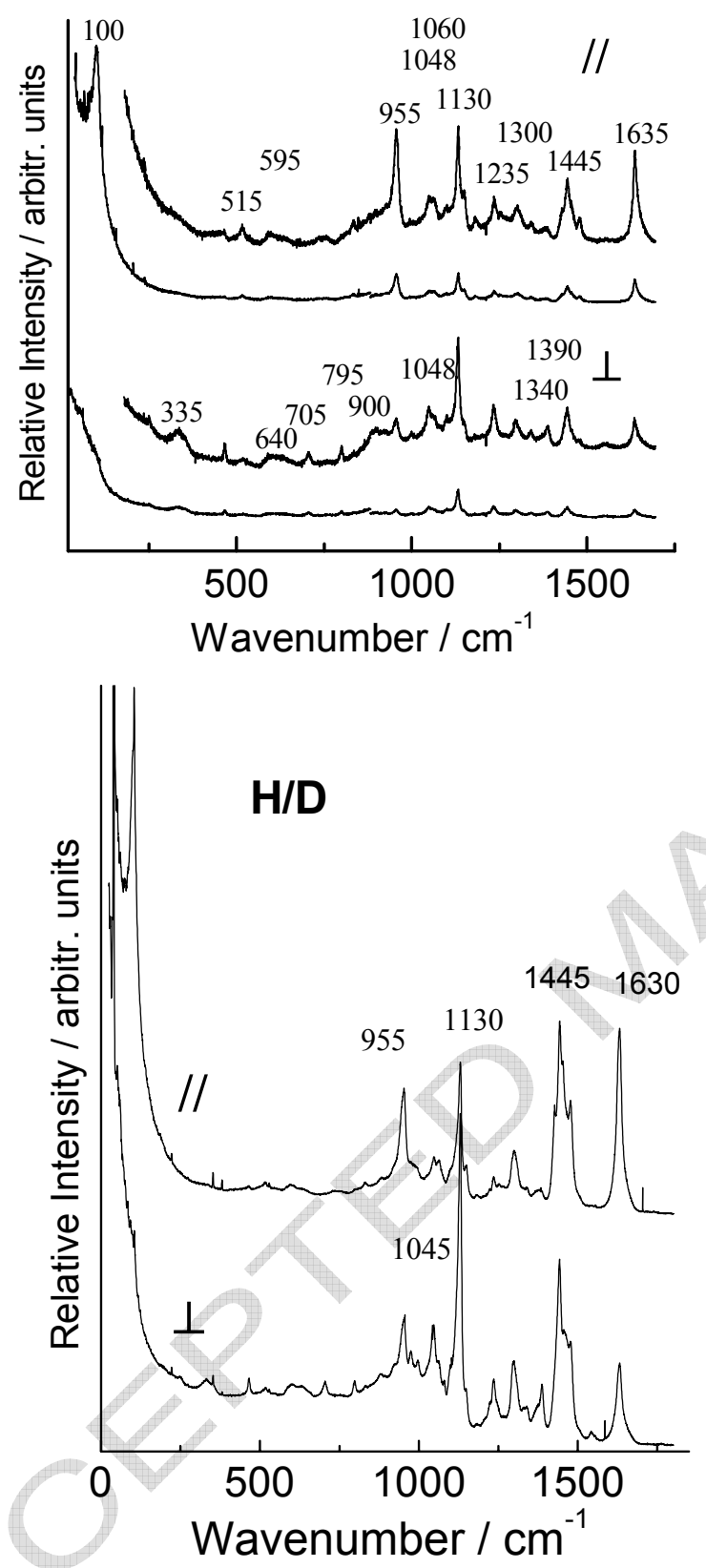

Fig 1 

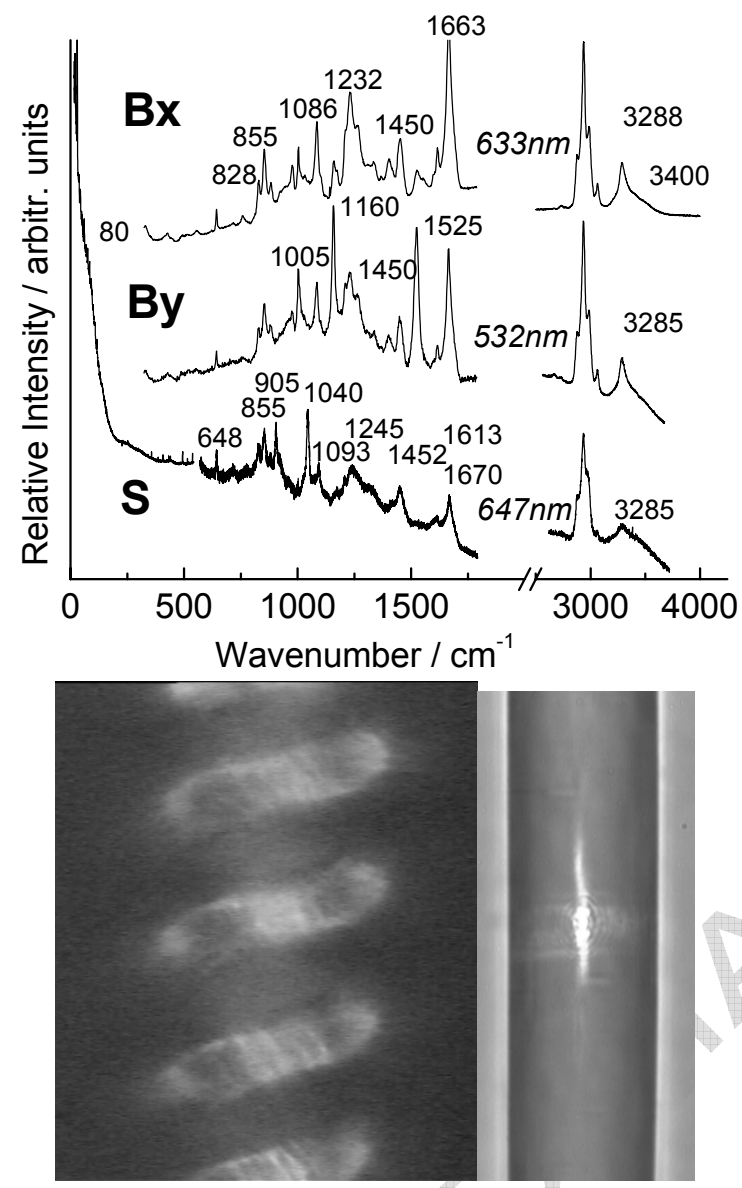

Fig2 


\section{ACCEPTED MANUSCRIPT}
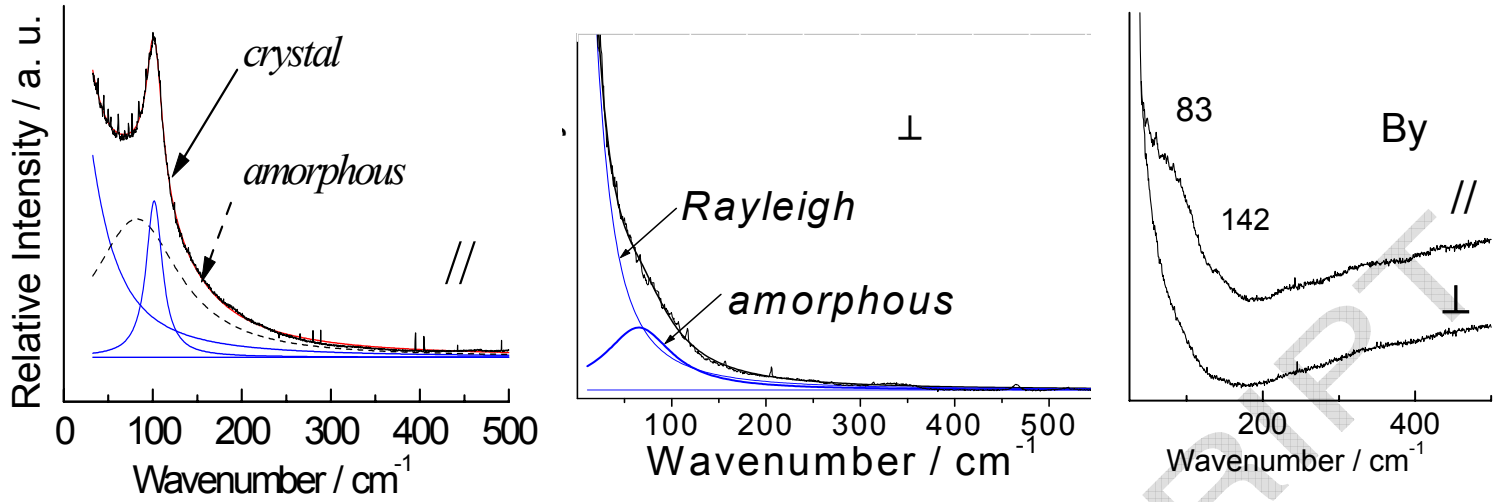

Fig3 


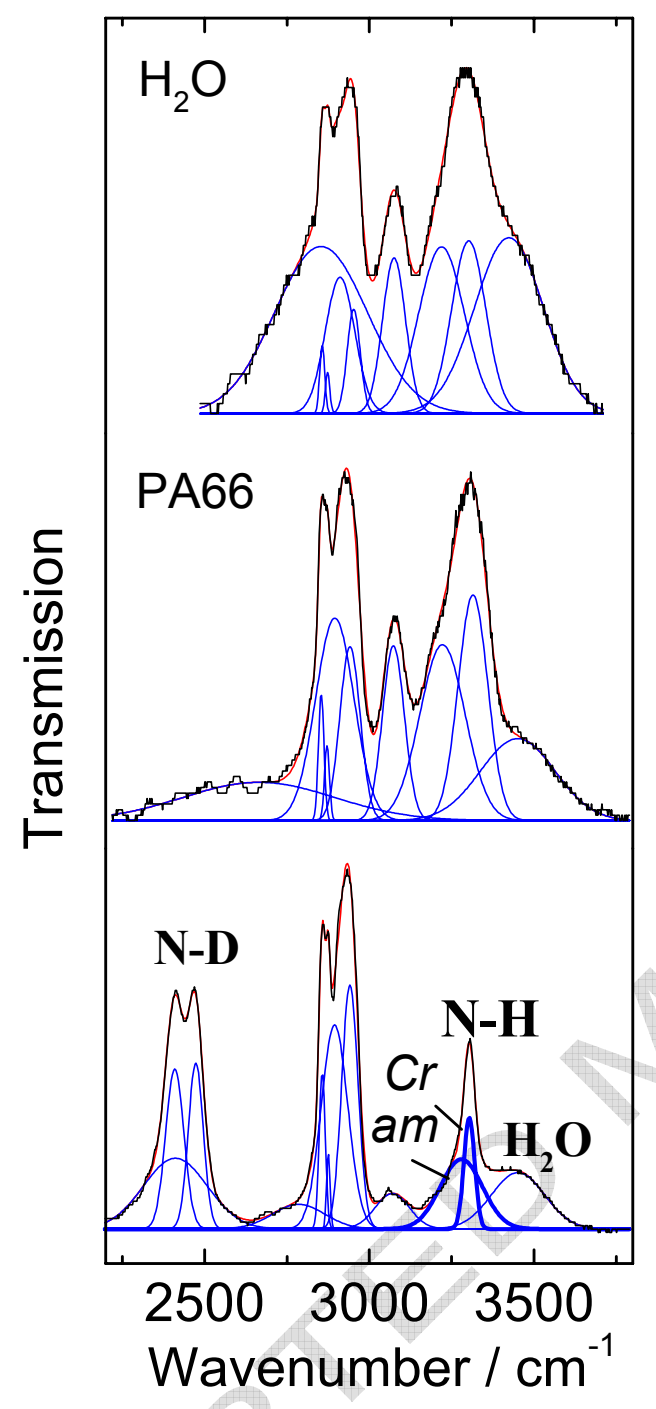

Fig4 

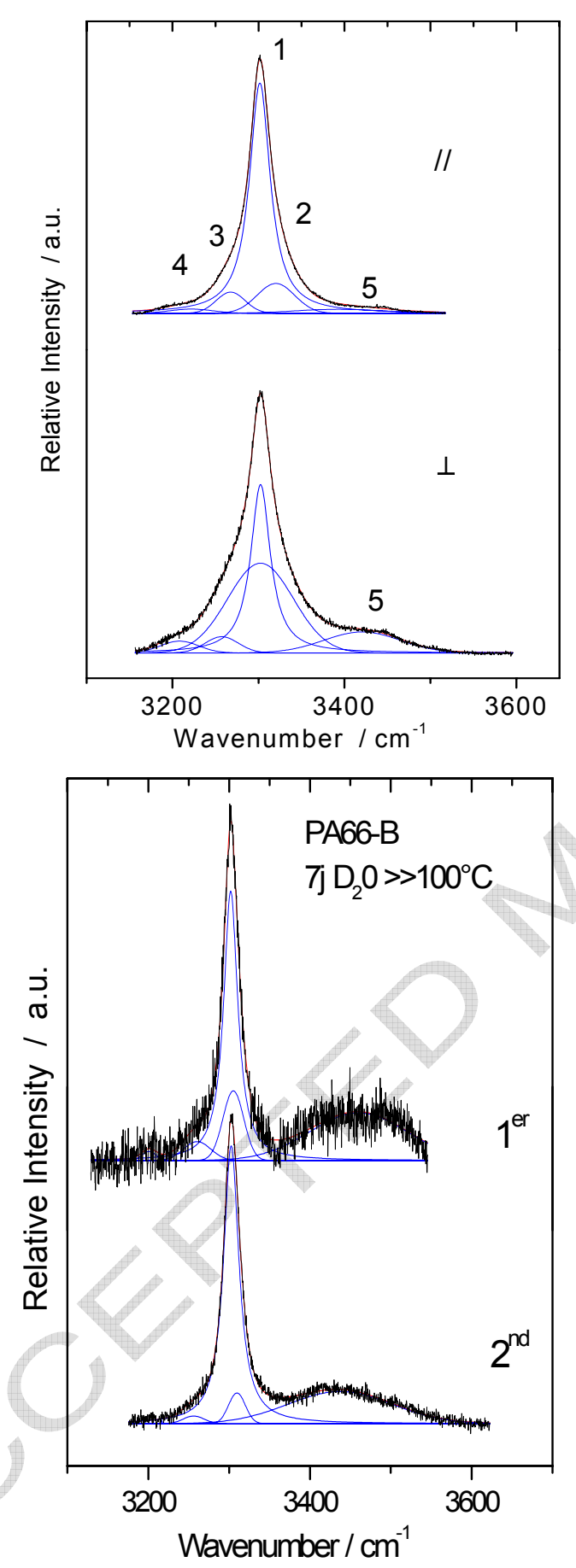

Fig5 


\section{ACCEPTED MANUSCRIPT}
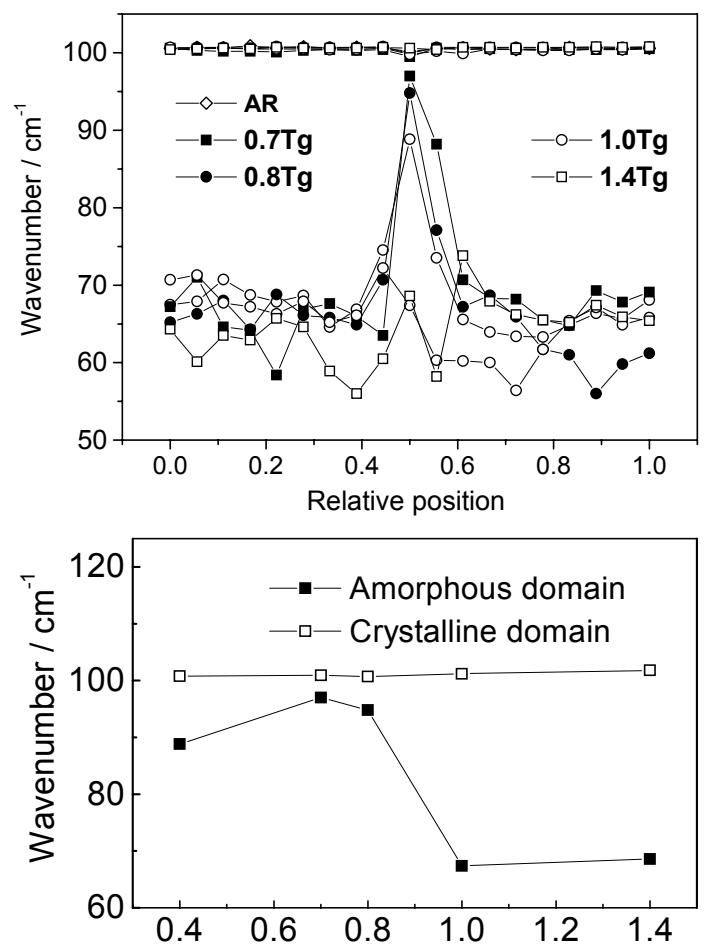

Relative annealing temperature : $\mathrm{T} / \mathrm{Tg}$

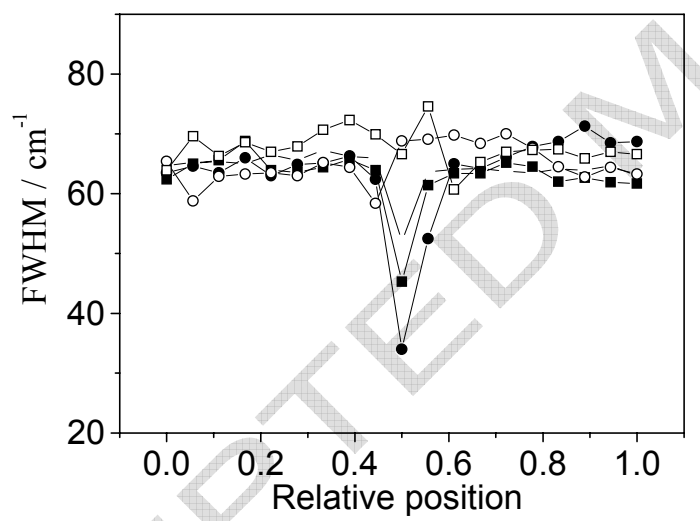

Fig6 

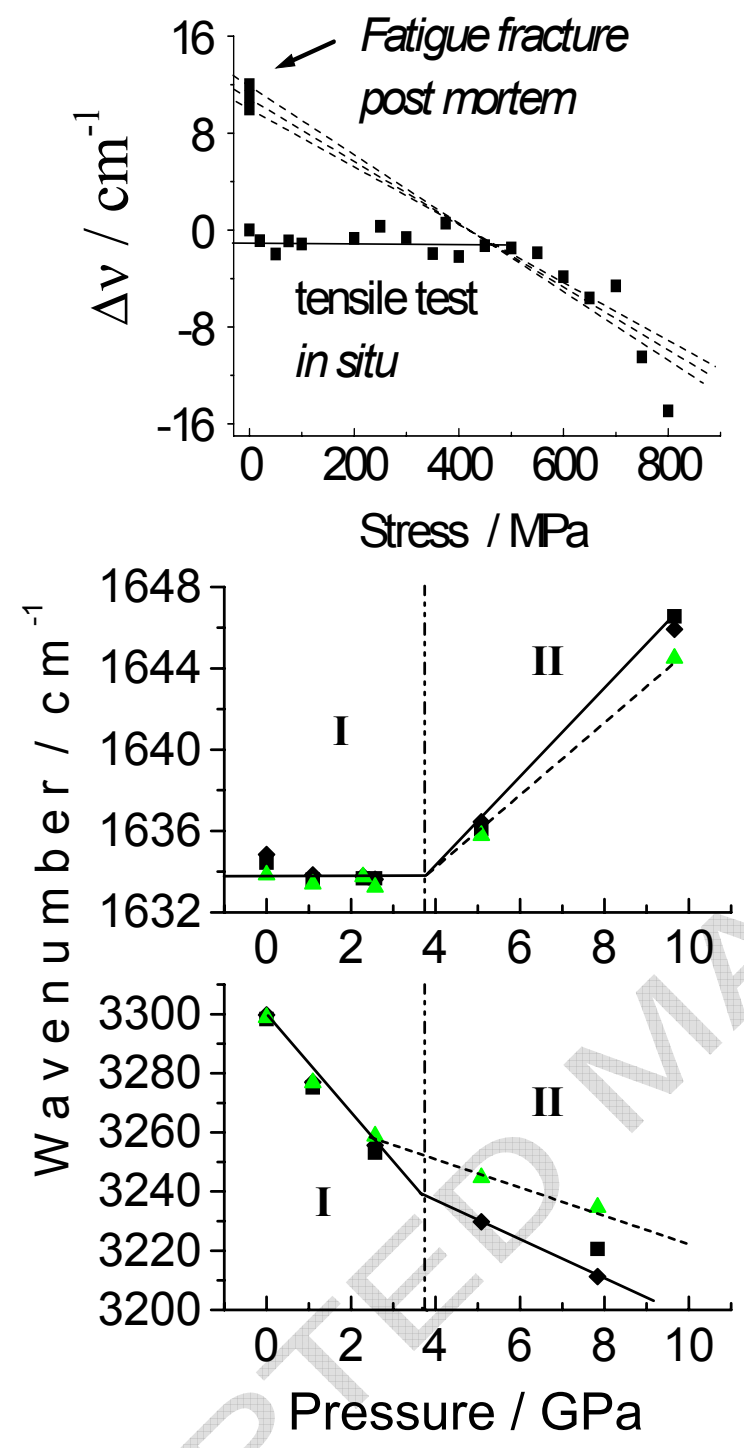

Fig7 